\title{
Straining Flow Spinning of Artificial Silk Fibers:
} A Review

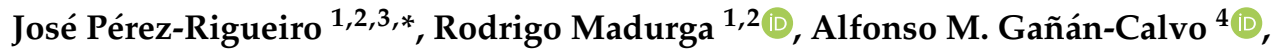 \\ Gustavo R. Plaza 1,2®), Manuel Elices 1,2, Patricia A. López ${ }^{1,2}$, Rafael Daza ${ }^{1,2}$, \\ Daniel González-Nieto ${ }^{1,3,5}$ and Gustavo V. Guinea ${ }^{1,2,3, *}$
}

1 Centro de Tecnología Biomédica, Universidad Politécnica de Madrid, 28223 Pozuelo de Alarcón, Madrid, Spain; rmadurga@gmail.com (R.M.); gustavo.plaza@upm.es (G.R.P.); m.elices@upm.es (M.E.); patricia.lopez@ctb.upm.es (P.A.L.); rafael.daza@upm.es (R.D.); daniel.gonzalez@ctb.upm.es (D.G.-N.)

2 Departamento de Ciencia de Materiales, ETSI Caminos, Canales y Puertos, Universidad Politécnica de Madrid, 28040 Madrid, Spain

3 Biomedical Research Networking Center in Bioengineering, Biomaterials and Nanomedicine (CIBER-BBN), Madrid, Spain

4 Departamento de Ingeniería Aeroespacial y Mecánica de Fluidos, Escuela Técnica Superior de Ingenieros, Universidad de Sevilla, 41092 Sevilla, Spain; amgc@us.es

5 Departamento de Tecnología Fotónica y Bioingeniería, ETSI Telecomunicaciones, Universidad Politécnica de Madrid, 28040 Madrid, Spain

* Correspondence: jose.perez@ctb.upm.es (J.P.-R.); gustavovictor.guinea@upm.es (G.V.G.); Tel.: +34-910-674-304 (J.P.-R.)

Received: 30 July 2018; Accepted: 1 October 2018; Published: 5 October 2018

\begin{abstract}
This work summarizes the main principles and some of the most significant results of straining flow spinning (SFS), a technology developed originally by the authors of this work. The principles on which the technology is based, inspired by the natural spinning system of silkworms and spiders, are presented, as well as some of the main achievements of the technique. Among these achievements, spinning under environmentally friendly conditions, obtaining high-performance fibers, and imparting the fibers with emerging properties such as supercontraction are discussed. Consequently, SFS appears as an efficient process that may represent one of the first realizations of a biomimetic technology with a significant impact at the production level.
\end{abstract}

Keywords: silk; regenerated fibers; fibroin; spidroin

\section{Introduction}

Like any great story, the study of spider and silkworm silks can be contemplated from a number of different perspectives [1], all of them fascinating. From its first appearance in the evolution of early Araneae [2] and the independent evolutionary event [3] that led to the production of silk fibers by some insects, most conspicuously from the Lepidoptera order, to the production of one of the toughest materials [4], the study of silk-based materials offers a complex picture of lessons for very different scientific areas. The recognition of these lessons has converted the bioinspired production of artificial silk-like materials into one of the leading research lines in the field of biomimetics.

The main event in natural spinning, as observed in spiders and silkworms, is the transition from a protein solution to a high-performance solid fiber. This process occurs in fractions of second and proceeds under extremely biosustainable, and thus environmentally friendly, conditions [5]. The success of this process depends on the careful design of the intervening elements, as well as on their coordinated action. Thus, one of the key elements of spinning is the peculiar sequence of the silk proteins, known as fibroins (or as spidroins when referred specifically to spider silk 
proteins). All silk fibroins show a common organization characterized by a large number of repeats of shortmotifs: (GAGAGS) ${ }_{n}$ in silkworm (Bombyx mori) silk [6], and $A_{n}$, (GGX) $n$ (where $X$ is often tyrosine or glutamine), (GPG) ${ }_{n}$ and (GA) ${ }_{n}$ in spider silks [7]. In addition to these repetitive motifs, fibroins show two extremely conserved $\mathrm{N}$ - and C-terminal domains [8,9], that act as $\mathrm{pH}$ switches and control the conformation and assembly of the proteins [10]. In this regard, it is assumed that at high values of $\mathrm{pH}$ the conformation of these terminal domains tend to favor the soluble state of the proteins, possibly in a dimeric state, while a decrease in $\mathrm{pH}$ leads to the assembly of the proteins into larger structures [11].

The dependence of the fibroin conformation and assembly on $\mathrm{pH}$ is exploited during the spinning process by a careful control of the $\mathrm{pH}$ values $[12,13]$, which vary from $\mathrm{pH} \approx 8.0$ in the gland sac, where the protein is stored, to $\mathrm{pH} \approx 5.0$ in the duct, where the fiber is formed. Additionally, it is also hypothesized that the concentration of certain ions such as $\mathrm{PO}_{4}{ }^{3-}, \mathrm{Na}^{+}$, and $\mathrm{Cl}^{-}[14,15]$ along the silk gland may also influence the assembly of the proteins. There is some debate on the exact nature of the fibroin assemblies in the gland and two possible models were proposed to account for the singular properties of the silk dope (fibroin solution), most significantly its low viscosity $[16,17]$ in spite of the large protein concentration found in the gland. A first model assumes that the silk fibroins form anisotropic structures that behave as a lyotropic liquid crystal [18]. A second model proposes the organization of the fibroin proteins in micellar structures, that are deformed along the silk gland [19]. It is believed that the actual natural spinning process might share characteristics of both models [10].

A larger consensus is found on the last steps of the spinning process in which the mechanical stresses to which the proteins are subjected seem to play a critical role $[20,21]$. Thus, it is assumed that the proteins, previously assembled inside the silk gland, undergo relative displacements that induce the alignment of the (GAGAGS) ${ }_{n}$ motif in silkworm silk and of the $\mathrm{A}_{n}$ in spider silk, and lead to the formation of $\beta$-nanocrystals. The $\beta$-nanocrystals result from the piling up of $\beta$-pleated sheets [22-24] and impart the material its structural integrity [25].

The efficiency of the natural process, and the number of possible new applications that might benefit from the availability of bioinspired silk fibers, naturally arose the interest in the artificial production of these materials. In this regard, although a significant number of spinning processes were proposed and analyzed, all of them can be grouped in one of three possible strategies [26]: (1) Wet spinning (small variations of wet spinning are represented by dry spinning and dry jet/wet spinning), (2) electrospinning, and (3) biomimetic spinning. Initial attempts were based on the wet spinning process in which a fibroin solution interacts with a coagulating bath, so that the solvent molecules are removed, resulting in the assembly of the silk proteins and in the formation of the fiber. It is believed that the first description of a wet spinning process for silk dates back to 1960 [27], in which fibers were produced from an aqueous fibroin solution using ammonium sulphate as coagulant. Almost three decades later, a similar approach was used by Ishizaka et al. [28], using orthophosphoric acid $\left(\mathrm{H}_{3} \mathrm{PO}_{4}\right)$ as solvent and a mixture of ammonium and sodium sulphate as coagulant. Subsequent attempts have varied the chemistry of the solvent or the coagulant while maintaining the principles of the process [29-32]. As indicated above, dry spinning represents a variation of wet spinning in which the solvent evaporates to a gaseous environment instead of being removed through the interaction between the dope and the coagulating bath. Artificial silk fibers with remarkable tensile properties were produced from highly concentrated fibroin solutions with this spinning technology $[33,34]$. Finally, in dry jet/wet spinning, the dry jet is forced to go through a small air gap before entering the coagulating bath. Such a dry jet/wet spinning procedure allowed the production of high-performance silk fibers from highly concentrated fibroin solutions containing $\mathrm{N}$-methylmorpholine $\mathrm{N}$-oxide (NMMO) to stabilize the dope [35].

An alternative to wet spinning and related processes is offered by electrospinning. In electrospinning, the dope jet is formed by the interaction of a dope solution with adequate electrical properties with an intense electric field, the solvent being evaporated into the environment [36]. Silk non-woven and mats can be efficiently produced through electrospinning, but the tensile properties of 
the individual fibers tend to be poor compared with those of the fibers produced through wet spinning and related techniques [37-39]. In addition to these conventional spinning techniques, the increased knowledge on the principles of the natural spinning process has led to the development of a number of biomimetic approaches that try to exploit these principles, for instance, the dependence of the natural assembly process on the $\mathrm{pH}$ of the solution [40-44].

In this context, straining flow spinning (SFS) was proposed and developed in a series of works [45-49] as a biomimetic approach to the production of artificial silk-based fibers. The SFS technique derives from flow focusing $[50,51]$ and wet spinning technologies, and its main characteristic is that the physicochemical environment of the dope, as well as the mechanical stresses to which the fibroins are exposed, are controlled by the interaction of the dope with a jet of focusing fluid. The present review is an attempt at a quick introduction to the SFS technology, in which its biomimetic principles are highlighted. The details of the different aspects summarized here can be found in much greater detail in the references cited above.

\section{Materials and Methods in Straining Flow Spinning Studies}

\subsection{Preparation of the Dope}

In our previous works on the development of the SFS technique, the dope consisted of a solution of silkworm (Bombyx mori) silk fibroin. Silk cocoons were degummed either in deionized water or in a $\mathrm{Na}_{2} \mathrm{CO}_{3}$ aqueous solution. Degumming in deionized water leads to fibroins with an average molecular weight of $100 \mathrm{kDa}$ (high molecular weight regenerated fibroin), which decreases to $55 \mathrm{kDa}$ (low molecular weight regenerated fibroin) in the $\mathrm{Na}_{2} \mathrm{CO}_{3}$ degumming solution. After degumming, the fibers were dissolved in a 9.4 M LiBr solution and dialyzed against deionized water. For a fibroin concentration higher than $4 \%$, a reverse dialysis process against polyethyleneglycol (PEG) was used. Dopes with a fibroin concentration higher than $8 \%$ were prepared with $1 \mathrm{M} \mathrm{CaCl}_{2}$ to stabilize the solution.

\subsection{Characterization of Silk Fibers}

The optical micrographs of the fibers were obtained with a Leica DMI3000B microscope with a $40 \times$ objective. Scanning electron microscopy (SEM) micrographs were obtained in a field emission SEM Auriga Zeiss, coupled to an energy dispersive X-ray spectroscopy (EDS) X Flash Detector 5010 (Bruker, Billerica, MA, USA). The infrared spectra were obtained with a Nicolet iS5 spectrometer equipped with an iD5 ATR complement. Briefly, tensile tests were used for the mechanical characterization of the samples as described elsewhere [52]. Tensile tests were performed in an Instron 4411 tensile testing machine, and forces were measured with a precision balance (Precisa XT220A). Wet-stretched samples [53] were prepared from the as-spun fibers by stretching the fibers up to $90 \%$ of the breaking of the fiber in water, fixing the deformed length and allowing the fiber to dry before testing. If required, the full details of the Materials and Methods can be found in the original references [45-49].

\section{Straining Flow Spinning: The Principles}

The basic setup for a SFS process is schematically shown in Figure 1. The core of the technique consists of a coaxial capillary-nozzle system (see inset), so that the nozzle presents a convergent profile in the outlet region. The dope and the focusing fluid flow along the capillary and in the region confined by the outer wall of the capillary and the inner wall of the nozzle, respectively. Upon reaching the end of the capillary, a jet of dope is formed and surrounded by the focusing fluid. Finally, both the dope and the focusing fluid enter a coagulating bath, which may have the same or a different composition to that of the focusing fluid. The flow rates of the dope and of the focusing fluid are controlled by syringe pumps, and the fiber is retrieved from the coagulating bath and wound on a set of take-up rollers from where it can be retrieved. A post-spinning drawing step may be added to the process by including a post-spinning roller, to which the fiber is transferred from the take-up roller. Post-spinning drawing is 
the result of imposing a higher speed to the post-spinning roller than to the take-up roller, which leads to the stretching of the fiber during its processing.

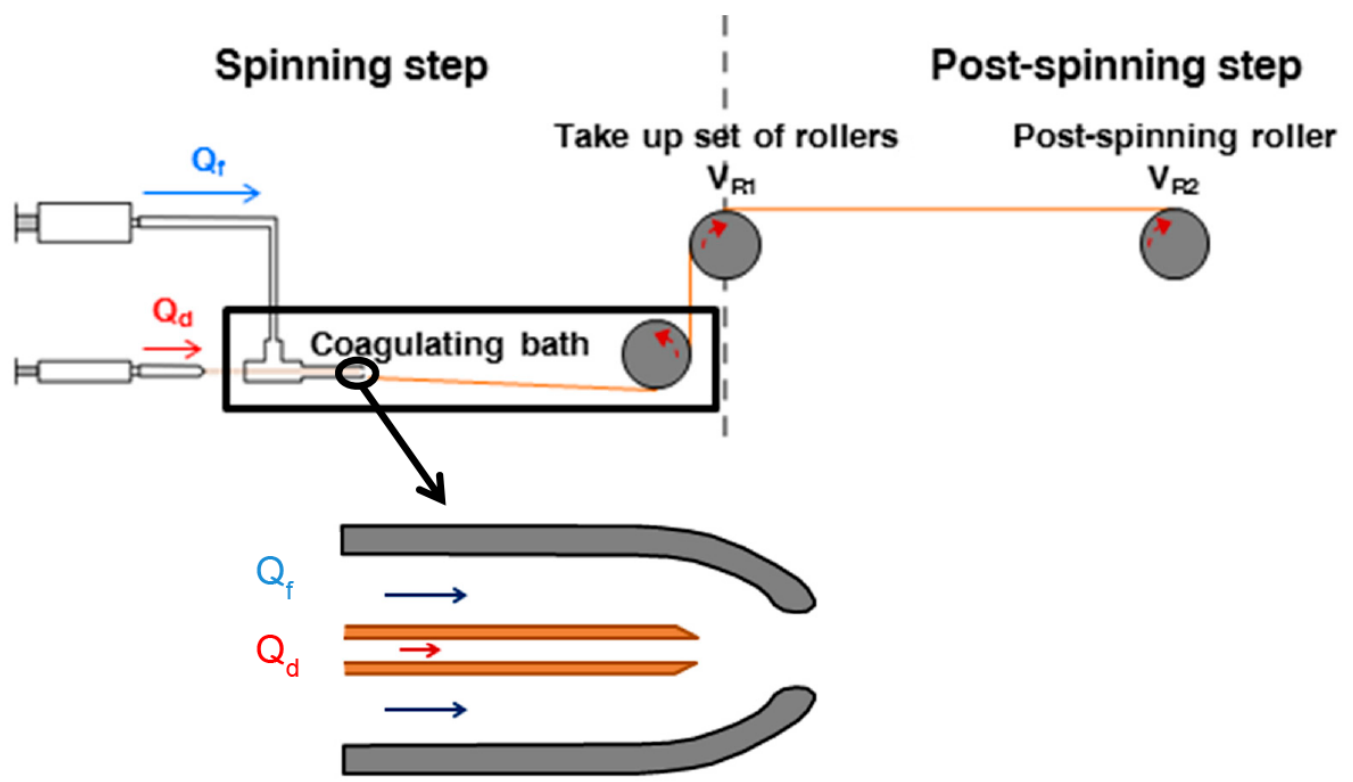

Figure 1. Schematic of a straining flow spinning process with its main elements. The inset shows a detail of the capillary-nozzle system in which the flow of the dope $\left(Q_{d}\right)$ and of the focusing fluid $\left(Q_{f}\right)$ are indicated. $V_{\mathrm{R} 1}$ : Velocity of the take-up roller; $V_{\mathrm{R} 2}$ : Velocity of the post-spinning roller.

The comparison of SFS with other spinning techniques reveals that one of the main singularities of the former is its versatility in terms of the number of parameters that control the spinning process. In this regard, as indicated in Table 1, the processing parameters in SFS can be divided into three groups: geometrical, hydrodynamic, and chemical. The geometrical parameters refer to the spatial assembly of the capillary-nozzle system and to the basic geometric features of their elements. The geometrical parameters comprise the inner and outer diameters of the capillary, the tapering angle at the end of the capillary, the distance between the end of the capillary and the nozzle outlet, the profile of the convergent region close to the nozzle outlet, and the nozzle outlet diameter. The hydrodynamic parameters correspond to the flow rates and speeds of the different components of the system and comprise flow rate of the dope, flow rate of the focusing fluid, velocity of the take-up roller, and in processes with a post-spinning drawing step, velocity of post-spinning drawing roller. The combined effect of the geometrical and hydrodynamic parameters controls the flow of both the dope and focusing fluids, and more importantly, their interaction. Finally, the chemical parameters comprise the composition of the dope, the composition of the focusing fluid and the composition of the coagulating bath. As indicated above, the focusing fluid and the coagulating bath often share a common composition, but SFS offers the possibility of using different compositions for both fluids.

Table 1. Summary of the geometrical, hydrodynamic, and chemical parameters that define a straining flow spinning process.

\begin{tabular}{|c|c|c|}
\hline Geometrical & Hydrodynamic & Chemical \\
\hline $\begin{array}{l}\text { - Capillary inner and outer diameter } \\
\text { - } \quad \text { Nozzle outlet diameter } \\
\text { - } \quad \text { Tapillary-nozzle outlet distance } \\
\text { - } \quad \text { Convergent profile of the nozzle } \\
\text { outlet region }\end{array}$ & $\begin{array}{l}\text { - Flow rate of the dope } \\
\text { - } \quad \text { Flow rate of the } \\
\text { focusing fluid } \\
\text { - } \quad \text { Velocity of the take-up roller } \\
\text { - Velocity of } \\
\text { post-spinning roller }\end{array}$ & $\begin{array}{l}\text { - Composition of the dope } \\
\text { - Composition of the } \\
\text { focusing fluid } \\
\text { - Composition of the } \\
\text { coagulating bath }\end{array}$ \\
\hline
\end{tabular}




\section{Straining Flow Spinning as a Biomimetic Process}

As indicated in the previous section, SFS is characterized by the large number of processing parameters that allow controlling the interaction between the dope and the focusing fluid, and eventually, the interaction between both fluids and the coagulating bath. It is precisely this interaction that lies at the basis of the development of SFS as a biomimetic technique. Conversely, the degrees of freedom present in SFS provide an optimum environment to discover what are the actual key factors that contribute to the extreme efficiency of the natural process.

Natural spinning in spiders and silkworms is the result of the combined effect of changes in the physicochemical environment and in the mechanical stresses to which the fibroin dope is exposed. Figure 2 schematically shows how the interaction between the dope and the focusing fluid mimics these changes in terms of the diffusion of chemical species between both fluids (Figure 2a) and of the deformations sustained by the dope jet (Figure 2b). As described for the natural spinning process, the transition from a protein solution to a solid fiber requires the removal of water molecules, initially present in the dope. This effect is favored by including dehydrating agents such as ethanol or PEG in the composition of the focusing fluid. In addition to the removal of water molecules, the formation of the solid fiber requires the concentration of several ions to vary, most importantly protons, along the silk gland and duct. This effect can be mimicked in the SFS process through the compositions of the dope and of the focusing fluid. Thus, the use of a mild acid in the composition of the focusing fluid is beneficial for the solidification of the fiber, probably through its effect on the $\mathrm{pH}$ switches of the fibroins. In turn, the removal of some components that stabilize the fibroin solution, such as $\mathrm{CaCl}_{2}$, may favor the formation of the solid fiber. In addition to the influence exerted by the chemistries of the different fluids, the flow lines and flow rates of the dope and of the focusing fluid also influence the diffusion by controlling, for instance, the rate to which fresh focusing fluid enters into contact with the dope jet. The influence of the flow lines and rates of the dope and focusing fluid is even more apparent on the deformation of the elementary volumes of the dope, which implies that these hydrodynamic features can be controlled through the geometrical and hydrodynamic parameters of the process. It should be mentioned, however, that the chemistry of the fluids also exerts a certain influence on the mechanical stresses exerted on the dope, in this case, mostly through the values of density and viscosity which, in turn, depend on the composition of the fluids.

The basic features indicated in Figure 2 will be presented in greater detail in the next section during the discussion of the influence of the different parameters on the outcome of the SFS process.

(a)
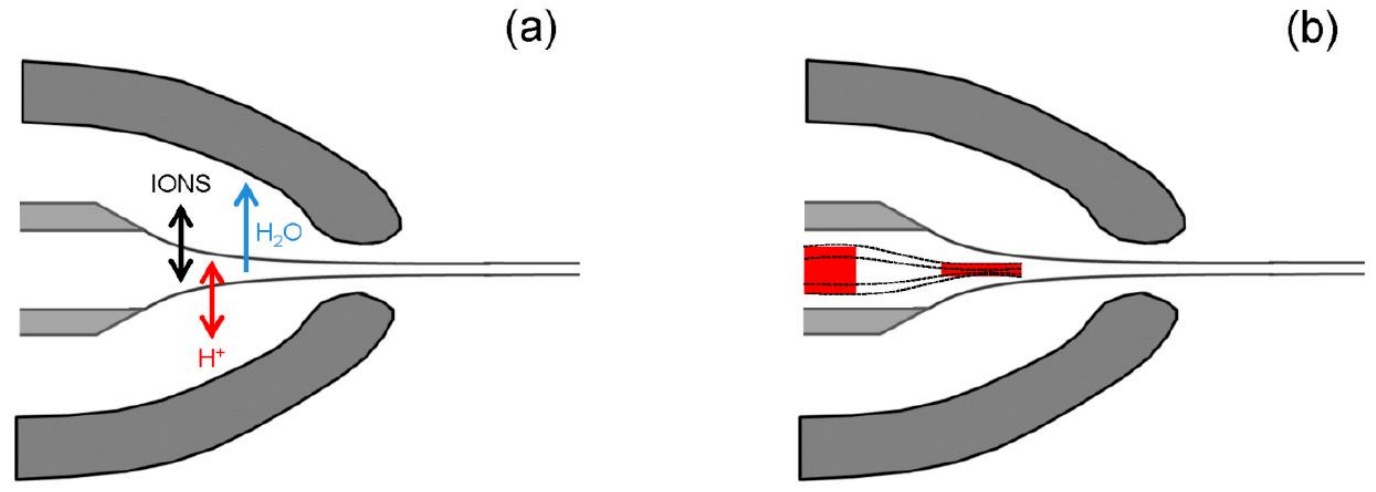

Figure 2. Schematic of the basic processes that result from the interaction between the dope jet and the focusing fluid. (a) Diffusion processes include the exchange of ions, including protons and the removal of water molecules from the dope to the focusing fluid. (b) The hydrodynamic interaction of both fluids results in the deformation of the dope jet. 


\section{Influence of the Spinning Parameters on the Regenerated Silk Fibers}

\subsection{Composition of the Dope}

Straining flow spinning allows the efficient production of fibers from aqueous solutions, so that water is the preferred solvent for the preparation of the fibroin dope. Besides, the full formulation of the dope is given by the sequence, or at least, by the average molecular weight of the fibroin proteins and by their concentration, as well as by the $\mathrm{pH}$ and by the possible addition of salts or other small chemical moieties to the solution.

When SFS is used to spin regenerated silkworm silk fibers, the average molecular weight of the fibroins depends on the particular conditions of the degumming process. Thus, larger proteins are obtained under milder degumming conditions so that, in particular, higher molecular weight proteins are retrieved if $\mathrm{Na}_{2} \mathrm{CO}_{3}$ is not added to the degumming solution. As a result of the damage induced in the proteins during degumming, the solubility of the silk proteins after degumming is smaller than that of the native protein. The decrease in solubility implies that regenerated silk solutions tend to be unstable at a protein concentration around 10\% $(w / v)$. Larger concentrations can be obtained, but a stabilizing agent such as $\mathrm{NMMO}[54,55]$ or $\mathrm{CaCl}_{2}[32,34]$ is required. If no buffer is added to the dope, the $\mathrm{pH}$ of the fibroin solution is in the range $\mathrm{pH} \approx 5.0$.

Figure 3 shows the influence exerted by the composition of the dope on the geometry of the fibers. Fibers produced from three different high molecular fibroin dopes (i.e., fibroin at a concentration of $4 \%$ $(w / v)$ in water, fibroin at a concentration of $8 \%(w / v)$ in water, and Ca-fibroin at a concentration of $16 \%$ in a $1 \mathrm{M} \mathrm{CaCl}_{2}$ aqueous solution (Ca-16\%)) are compared [49] in terms of their overall geometry and fracture surfaces after tensile testing. All fibers were produced using an $80 \%$ ethanol/20\% $1 \mathrm{M}$ acetic acid solution in water, so that the final acetic acid concentration was $0.2 \mathrm{M}$ for both the focusing fluid and the coagulating bath. The rest of the spinning parameters were kept constant during the production of the different fibers.

The possibility of spinning from an aqueous dope with a low protein concentration such as $4 \%$ $(w / v)$, one order of magnitude smaller than the concentration in the silkworm silk gland, is a feature characteristic of SFS. However, the fractographic analysis of the $4 \%$ sample, reveals the presence of some voids in the fracture surface (Figure $3 \mathrm{~b}$ ). Increasing the protein concentration to $8 \%$ leads to some irregularities in the fiber and a significant necking is observed when the fiber is tensile tested until breaking (Figure 3b). Finally, increasing the fibroin concentration up to $16 \%(w / v)$ was possible with the addition of $1 \mathrm{M} \mathrm{CaCl}_{2}$ to the dope. Samples produced from this dope are homogenous and their diameter is larger than that of the fibers spun from dopes with a smaller protein concentration (Figure 3a). The fractographic analysis of the Ca-16\% sample reveals an essentially flat fracture surface (Figure 3b), where no void or clear defects can be identified.

The high concentration of $\mathrm{Ca}^{2+}$ ions in the dope offers the possibility of checking the diffusion of different chemical moieties between the dope and the focusing fluid. In particular, the possible presence of calcium in the fibers can be assessed through EDS. Figure 4a shows a SEM micrograph of silk fibers spun from the 16\%-Ca dope under the spinning conditions indicated above, and Figure $4 \mathrm{~b}-\mathrm{e}$ show the EDS mapping for the channels corresponding to carbon (Figure 4b), oxygen (Figure 4c), nitrogen (Figure 4d), and calcium (Figure 4e). As expected for protein fibers, the EDS mapping reveals the presence of carbon, oxygen, and nitrogen in the fibers, while no calcium is observed up to the resolution limit of the technique. This result shows that the $\mathrm{Ca}^{2+}$ ions initially present in the dope solution are removed as an effect of the interaction between the dope and the focusing fluid (possibly with the coagulant bath, too). The possible effect of this removal in the transition from protein solution to a solid fiber will be discussed in the next subsection. 
(a)

(b)

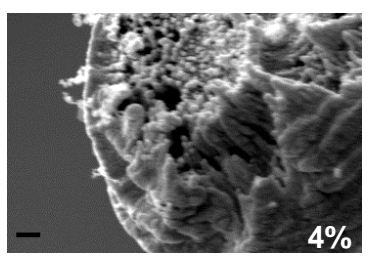

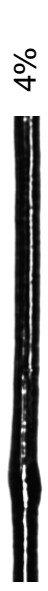
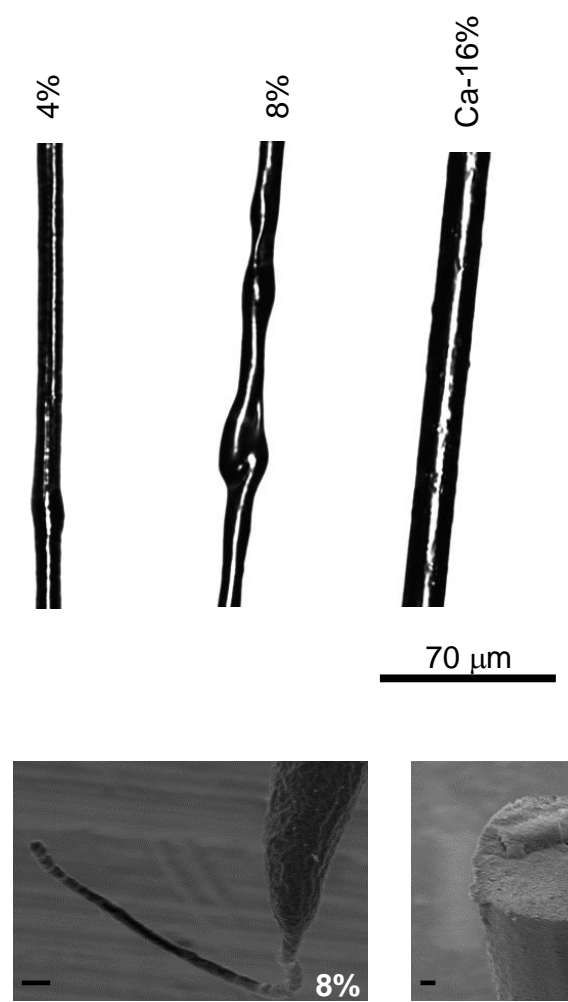

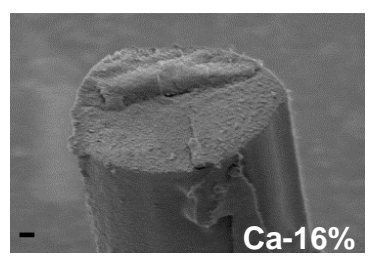

Figure 3. Morphology and fractographic analysis of regenerated silk fibers spun from dopes with different compositions. (a) Morphology of the fibers observed using optical microscopy. (b) Scanning electron microscopy (SEM) migrographs of the fracture surfaces of tensile tested samples. The percentage indicates the fibroin concentration in the dope and $\mathrm{Ca}$ indicates that the dope contains $\mathrm{CaCl}_{2}$ at $1 \mathrm{M}$ concentration. The $4 \%$ sample shows the presence of voids in the fracture surface. The $8 \%$ sample shows the considerable necking undergone by the fiber prior to fracture. The $16 \%$ sample shows an essentially flat fracture surface. The scale bar in the SEM micrographs corresponds to $1 \mu \mathrm{m}$.
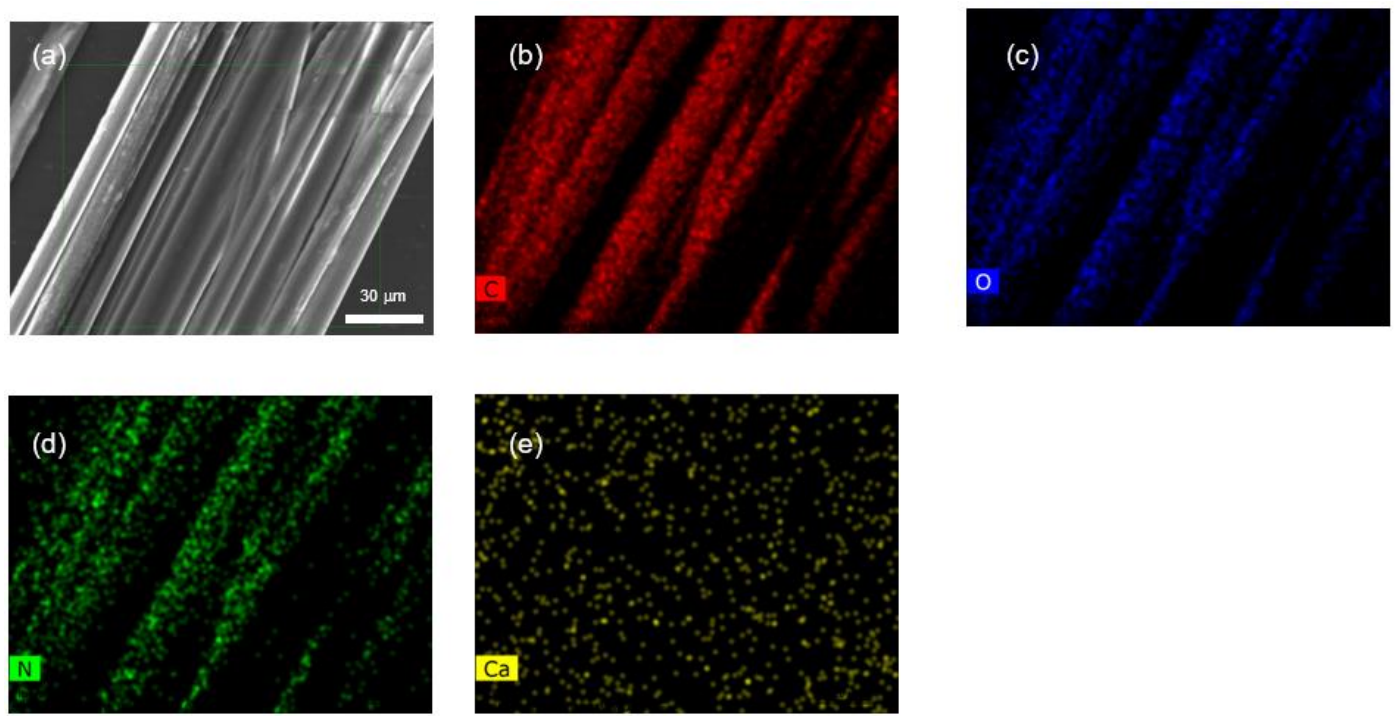

Figure 4. Elementary analysis of fibers produced by straining flow spinning. (a) Scanning electron micoscopy micrograph of regenerated silk fibers spun from the Ca-16\% dope and its elementary energy dispersive X-ray spectroscopy (EDS) mapping for (b) carbon, (c) oxygen, (d) nitrogen, and (e) calcium. In spite of the high concentration of $\mathrm{Ca}^{2+}$ ions in the dope, no calcium remains in the fibers upon spinning to the resolution limit of the technique. 


\subsection{Composition of the Focusing Fluid}

Following the schematic depicted in Figure 2a, the interaction between the dope and the focusing fluid must create the conditions that favor the assembly of the proteins and eventually lead to the transition from the protein solution to the solid fiber. Since one of the key processes for the assembly of the proteins is the substitution of protein-water interactions for protein-protein interactions, the removal of water molecules from the dope is supposed to play a critical role in this transition. Water is removed from the dope by including a dehydrating agent in the composition of the focusing fluid, so that a competition is established between the fibroin proteins and the dehydrating agent for the water molecules initially present in the dope. A similar dehydrating mechanism is common in the conventional wet spinning of regenerated silk fibers and a number of alcohols are usually employed in the coagulating bath including methanol [29-31] and ethanol [56]. These alcohols differ in their affinity towards water molecules, which is higher in methanol, although at the expense of using a highly toxic chemical. In this regard, SFS allows avoiding the use of harsh or toxic solvents in the focusing fluid, so that the preferred choices are usually mild alcohols such as ethanol, isopropanol, and even, PEG.

However, the analysis of the natural spinning process shows that the formation of the solid fiber does not result exclusively from the mere removal of the water molecules that act as solvent in the dope. The presence of the $\mathrm{pH}$ switches at the $\mathrm{N}$ - and C-terminal domains of the protein imply that the protein conformation depends on the $\mathrm{pH}$ of the solution, as well as on the concentration of several ions. In turn, conformational changes do control the assembly process of the fibroins to a large extent. In this regard, and although the regenerated fibroins may suffer the cleavage of certain regions during degumming, the regenerated system is still sensitive to the physicochemical conditions of the protein solution.

Straining flow spinning offers the possibility of modifying the physicochemical conditions of the fibroins in a controlled way through the diffusion of chemical moieties from and to the dope and the focusing fluid. Thus, addition of a mild acid (acetic acid) to the focusing fluid appears to enhance the coagulating effect of the focusing fluid compared with the same composition with no added acid. Besides, as shown in Figure 4, the interaction between the dope jet and the focusing fluid promotes the removal of the $\mathrm{Ca}^{2+}$ ions, which stabilize the fibroin solution at concentrations higher than $8 \%(w / v)$, and is likely to contribute further to the formation of the solid fiber.

Figure 5a shows the effect of different compositions of the focusing fluid on the morphology and microstructure of the regenerated fibers. Three different compositions of the focusing fluid are compared: ethanol, isopropanol, and $80 \%$ ethanol $/ 20 \%$ acetic acid solution in water (Ac-Et80). As shown in Figure 5, the homogeneity of the fibers largely depends on the focusing fluid used during the spinning process: fibers spun with ethanol appear as largely inhomogeneous, those spun with isopropanol appear slightly more homogeneous, and homogeneity is significantly improved when the Ac-Et80 mixture is used as focusing fluid. Usage of this latter focusing fluid implies a change in the $\mathrm{pH}$ from the initial value of $\mathrm{pH} \approx 5.0$ to a final value of $\mathrm{pH} \approx 4.0$.

The effect of different focusing fluids on the fibers is also apparent when the microstructure of the fibers is considered. Figure $5 b$ compares the amide I peak obtained by Fourier-transform infrared spectroscopy (FTIR) of the regenerated fibers shown in Figure 5a and a degummed natural silkworm silk fiber. The amide I peak of a degummed natural silkworm silk fiber shows a peak at $1620 \mathrm{~cm}^{-1}$, which indicates the dominant contribution of the $\beta$-pleated secondary structure characteristic of silk fibers [25] to the amide I peak. In contrast, regenerated fibers spun with ethanol show a much broader peak due to the higher contribution of random coil and helical conformations at around $1640 \mathrm{~cm}^{-1}$ in comparison with the contributions of these secondary structure to the spectrum of the natural silk fibers. Interestingly, regenerated fibers spun with isopropanol exhibit a sharp peak, but displaced with respect to the natural fibers to a wavenumber of $1640 \mathrm{~cm}^{-1}$. Finally, a sharp peak at $1620 \mathrm{~cm}^{-1}$ is observed in regenerated fibers spun with Ac-Et80, although these regenerated samples present a shoulder at higher wavelengths that is not observed in the natural material suggesting a higher proportion of random coil and helical secondary structures in comparison with the natural material. 
(a)

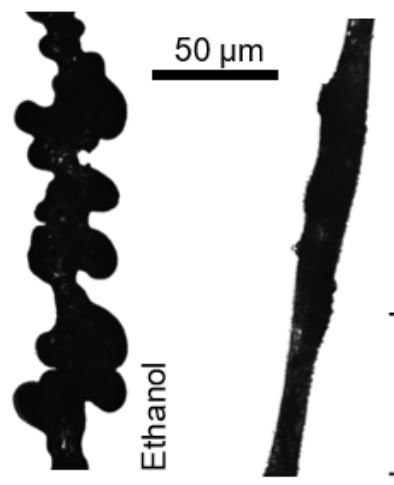

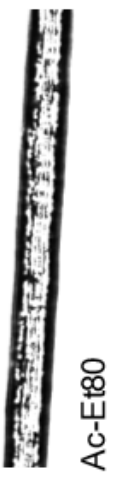

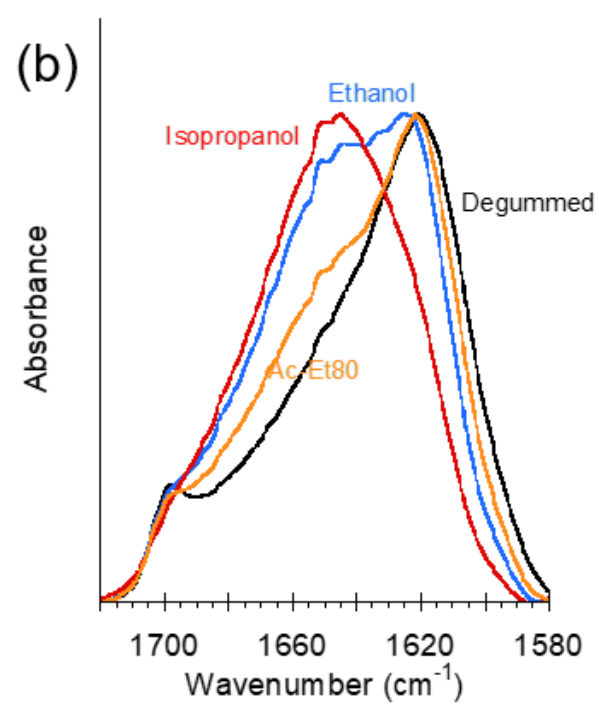

Figure 5. Morphology and Fourier-transform infrared spectroscopy (FTIR) spectra of regenerated silk fibers spun using different focusing fluid chemistries. (a) Morphology of the fibers observed using optical microscopy. (b) FTIR of the silk fibers in (a) shows amide I peaks between 1580 and $1720 \mathrm{~cm}^{-1}$. The FTIR spectrum of a degummed natural silkworm silk fiber (black line) is shown for comparison.

It is worth mentioning that the previous discussion on the requirements to the focusing fluid can be applied to a large extent to the coagulating bath fluid. As indicated above, very often the focusing fluid and the coagulating bath share a common composition, however, in contrast to other spinning techniques, SFS allows the employment of different chemistries for the focusing fluid and for the coagulating bath if necessary.

\subsection{Influence of the Geometrical and Hydrodynamic Parameters}

Besides the large flexibility for the production of regenerated silk fibers offered by SFS through the various combinations of dope and focusing fluid chemistries, the control exerted in the process through the hydrodynamic parameters is a feature characteristic of the technique. In addition, the hydrodynamic parameters can be varied in real time during the spinning process. This particularity of the technique was recognized in previous works where it was found that parameters such as the diameter of the fibers were largely controlled by the values of the flow rate of the dope and of the focusing fluid [47]. In this regard, the possibility of controlling the stresses exerted on the dope jet, which can be estimated from Equation (1), is a unique feature to SFS compared with other spinning techniques:

$$
\Delta P \approx \rho_{f} \frac{Q_{f}^{2}}{D_{1}^{4}}
$$

where $\rho_{f}$ is the density of the focusing fluid, $Q_{f}$ is the flow rate of the focusing fluid, and $D_{1}$ is the diameter of the nozzle outlet.

Figure 6 shows the influence of the hydrodynamic parameters: flow rate of the dope $\left(Q_{d}\right)$, flow rate of the focusing fluid $\left(Q_{f}\right)$, and velocity of the take-up roller $\left(V_{R 1}\right)$ in a single spinning process. In all cases, a value of $V_{R 1}$ was fixed between $1 \mathrm{~m} / \mathrm{min}$ and $4 \mathrm{~m} / \mathrm{min}$ (the maximum $V_{R 1}$ of the take-up roller in the configuration of the spinning device) and the values of $Q_{d}$ and $Q_{f}$ were varied, while retrieving the fibers in the take-up roller. As shown in Figure 6, three regions can be defined: (i) at low values of $Q_{f}$, there is a "non-spinnable" region, in which the fibers either do not form at all or break when transferred to the take-up roller; (ii) at high values of $Q_{f}$, another region referred to as "low $V_{R 1}$ " is defined, in which the rate of spinning is larger than the speed of the take-up roller and the fiber accumulates in the coagulating bath; and (iii) a "spinnable" region is defined, in which the fiber can be spun continuously and retrieved from the take-up roller. In addition to defining the conditions of the 
spinnable region, different values of the flow rate of the dope and of the focusing fluid may lead to fibers with different morphologies, as observed for the fibers spun under the conditions indicated by the yellow circles in Figure 6.

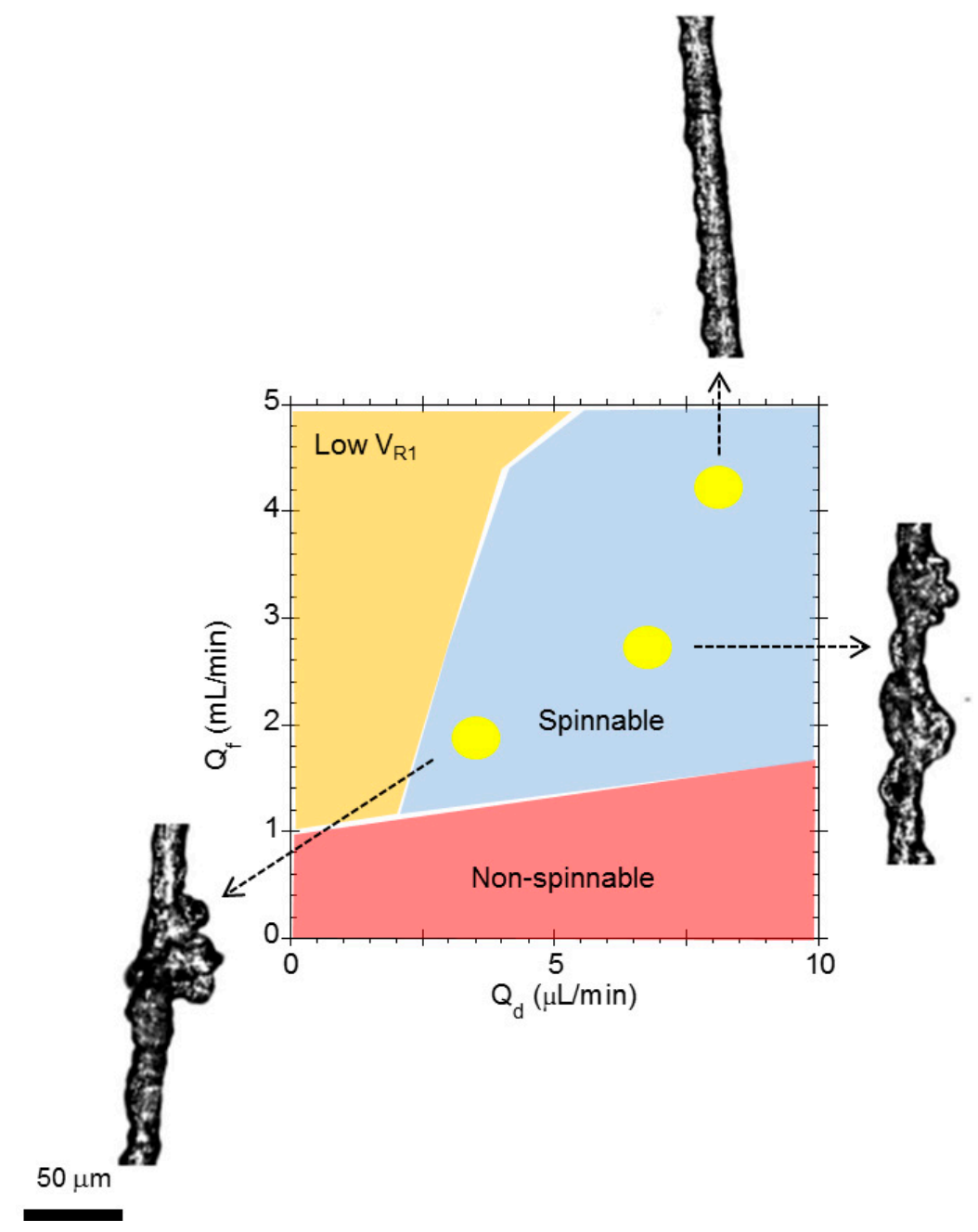

Figure 6. Chart of the spinning processes as determined by hydrodynamic parameters. The compositions of the dope and of the focusing fluid are kept fixed for all spinning processes in the chart. Three regions are defined and referred to as non-spinnable, spinnable, and low $V_{R 1}$. In the non-spinnable region, the fiber either does not form or breaks upon collection on the take-up roller. In the spinnable region, the fiber can be continuously spun and collected on the take-up roller. Finally, in the low $V_{R 1}$ region the fiber is formed, but accumulates in the coagulating bath. The morphologies of three fibers produced under different hydrodynamic conditions are shown, and the set of hydrodynamic conditions for spinning each fiber is indicated by a yellow circle in the chart. $Q_{d}$ : Flow rate of the dope; $Q_{f}$ : Flow rate of the focusing fluid; $V_{R 1}$ : Speed of the take-up roller.

\section{The Quest for High-Performance Regenerated Silk Fibers}

Straining flow spinning offers a wide range of possibilities both in terms of the spinning conditions compatible with the technique and of the properties of the spun regenerated fibers. In this regard, the initial development of the technique followed two main guidelines: (i) the use of mild and environmentally friendly chemistries for both the dope and the focusing fluid (and/or coagulating bath); and (ii) the identification of a set of conditions that lead to the production of high-performance fibers with a work to fracture comparable to that of natural silkworm silk $\left(\approx 70 \mathrm{MJ} / \mathrm{m}^{3}\right)$. In particular, the conditions required to reach the high values of work to fracture $\left(W_{f}\right)$ were difficult to identify 
because of the enormous parameter space between the sets of spinning conditions summarized in Table 1 . The selection of a suitable subset of processing parameters again followed the biomimetic approach used at the inception of SFS.

As indicated above, SFS allows spinning from regenerated silk fibroin with two different distributions of molecular weights, namely low and high molecular weights. Besides, fibers can be produced from dopes with protein concentrations as low as $4 \%(w / v)$, up to $16 \%(w / v)$, and possibly higher. Since the natural system requires extremely high molecular weight proteins at high concentrations, dopes were prepared from the high molecular weight regenerated fibroin at a concentration of $16 \%(w / v)$. Such a high concentration required the addition of $1 \mathrm{M} \mathrm{CaCl}_{2}$ to the dope solution to produce a stable protein solution in water.

Preliminary results from spinning processes using ethanol and isopropanol as focusing fluids showed that even these relatively mild dehydrating agents led to an abrupt solidification process, as revealed by the inhomogeneity observed in the fibers shown in Figure 5. Consequently, the usage of even milder coagulating chemistries was explored. In particular, a 30\% PEG solution in water and a mixture of $80 \%$ ethanol and $20 \%$ acetic acid in water (Ac-Et80) with a final concentration of $0.2 \mathrm{M}$ of acetic acid were employed both as focusing fluid and coagulating bath.

Finally, after fixing the chemistries of the dope and of the focusing fluid, a screening was performed on the geometrical and hydrodynamic parameters of the system [47] in order to identify the set conditions that led to high-performance fibers. Three sets of spinning conditions were selected and combined either with PEG [45] (Figure 7) or with the Ac-Et80 mixture [45,48] (referred to as Et-A and Et-B, respectively; Figure 7). In this case, Et-B fibers were produced with a flow rate of the focusing fluid $\left(Q_{f}=2.5 \mathrm{~mL} / \mathrm{min}\right)$ that is five times higher than that of the Et-A condition $\left(Q_{f}=0.4 \mathrm{~mL} / \mathrm{min}\right)$.

(a)

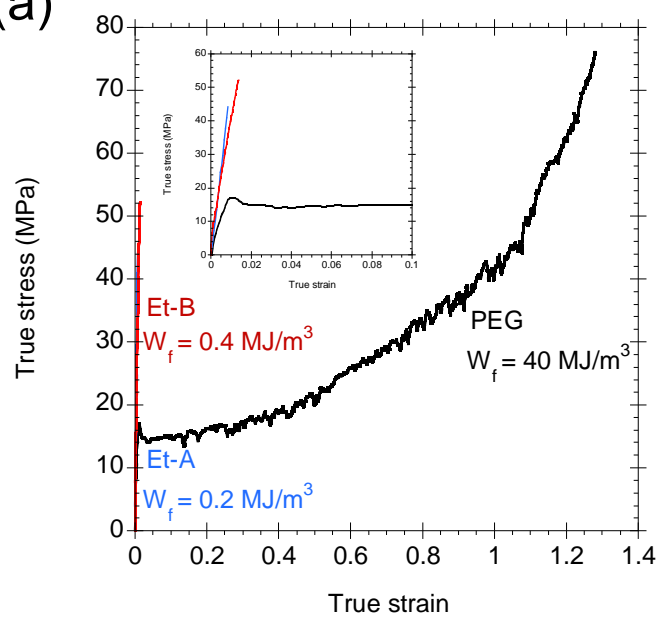

(b)

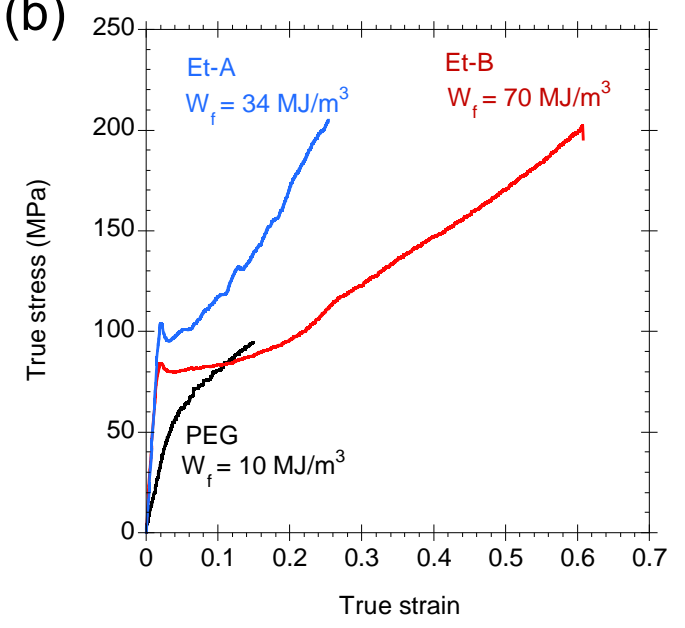

Figure 7. True stress-true strain curves of regenerated silk fibers produced by straining flow spinning and tested in air. Coagulating bath and focusing fluid for Et-A and Et-B samples: mixture of $80 \%$ ethanol and $20 \%$ acetic acid solution. Coagulating bath and focusing fluid for polyethyleneglycol (PEG) sample: $30 \%$ PEG in water. (a) As-spun fibers. The inset shows the true stress-true strain curves at low values of strain. (b) Wet-stretched fibers after drying. The spinning conditions are indicated in the text and the work to fracture $\left(W_{f}\right)$ of each fiber is shown here.

Figure 7a compares the true stress-true strain curves of the as-spun fibers using the three sets of conditions. The insert shows a close-up of the curves at low true strain values. As observed with the morphology, the fracture surfaces and microstructure of the fibers, large differences in the tensile properties of the fibers are observed as a function of the detailed processing parameters. In particular, the PEG sample shows a remarkable value of work to fracture of $W_{f}=40 \mathrm{MJ} / \mathrm{m}^{3}$ (half of the value of the natural material) that, to the best of our knowledge, is the highest work to fracture of any regenerated silkworm silk fiber not subjected to any post-spinning treatment. In contrast to this high 
value, the samples coagulated in Ac-Et80 show a brittle behavior until fracture with values of $W_{f}$ smaller than $1 \mathrm{MJ} / \mathrm{m}^{3}$.

Previous works on regenerated silkworm silk fibers showed that the tensile properties of initially brittle fibers can be considerably improved by subjecting the fibers to a wet-stretching process (see Section 2). Consequently, fibers spun with the three sets of conditions were wet-stretched up to a $90 \%$ of their breaking strain in water, allowed to dry, and tested. The true stress-true strain curves of the wet-stretched fibers are shown in Figure $7 \mathrm{~b}$. It is apparent that wet-stretching worsens the tensile properties of the PEG sample, but it increases the mechanical behavior of the Et samples (i.e., samples with Ac-Et80 focusing fluid and coagulant) considerably. Thus, sample Et-A reaches a remarkable value of $W_{f}=34 \mathrm{MJ} / \mathrm{m}^{3}$ and sample Et-B reaches a value of $W_{f}=70 \mathrm{MJ} / \mathrm{m}^{3}$, comparable to that found in the natural material. Wet-stretching is an efficient way of modifying the tensile properties of the fibers in the laboratory, but it is difficult to implement on an industrial scale. Consequently, subsequent studies were undertaken that proved the equivalence between the wet-stretching process and a post-spinning drawing step during the processing of the fibers [48]. Therefore, the combination of the basic SFS setup and a post-spinning drawing step constitutes an efficient procedure for the mass production of high-performance regenerated silk fibers.

Finally, several previous studies had shown that regenerated silkworm silk fibers can be endowed with the ability to supercontract [35], a feature characteristic of spider silk, which is not exhibited by natural silkworm silk fibers. Supercontraction implies the existence of a ground state, to which the fiber can return independently from its previous loading history by being immersed in water. Supercontraction is assessed through recovery tests in which the fiber is stretched to a certain value of strain, and then is allowed to contract in water, dried, and tested in air. The concurrence of the true stress-true strain curves after the fiber is allowed to supercontract and dried is the evidence that the fiber shows a proper ground state. Figure 8 shows a recovery test on a fiber spun under Et-A conditions and subjected to two stretching supercontraction cycles, before being tested to breaking. The immersion in water and contraction step after being stretched in air is indicated by the light blue arrows in Figure 8. As indicated above, the concurrence of the true stress-true strain curves is an indication of the existence of a ground state in the Et-A regenerated silkworm silk fibers.

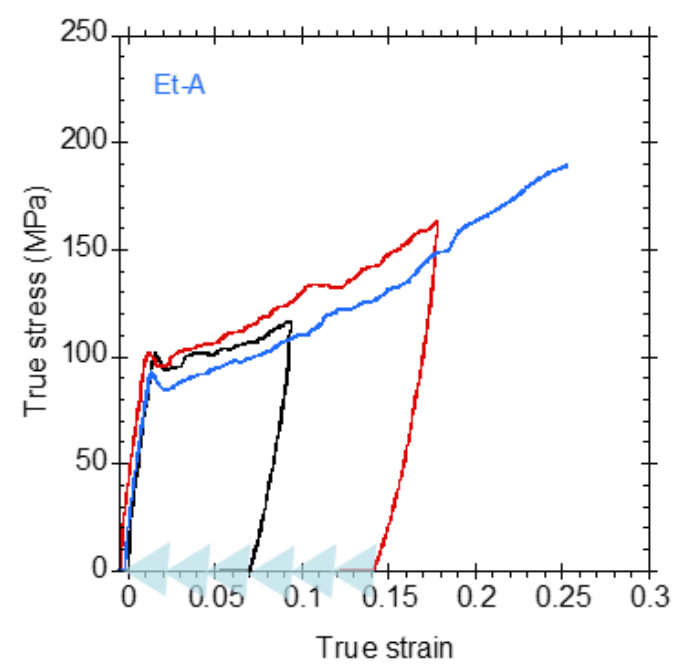

Figure 8. Recovery test of an Et-A regenerated silk fiber. Coagulating bath and focusing fluid for Et-A: mixture of $80 \%$ ethanol and $20 \%$ acetic acid solution. The fiber is stretched in air in a first cycle up to a strain of 0.1 (black curve), immersed in water and allowed to supercontract. Subsequently, the fiber is stretched up to a strain of 0.18 (red curve) and allowed to supercontract again. The contraction steps in water between each cycle of stretching in air are indicated by the light blue arrows on the true strain axis. Finally, the fiber is tensile tested up to breaking (blue curve). The concurrence of all the curves proves the supercontraction ability of this fiber. 


\section{Conclusions}

Straining flow spinning represents an efficient biomimetic approach for the production of silk-based artificial fibers. The formation of the solid fiber from the protein solution is the result of the interaction of the dope jet with a second fluid (focusing fluid), and possibly, with a coagulating bath. In turn, the interaction between both fluids is controlled by the geometrical setup of the device, as well as by the hydrodynamic parameters employed. The large number of processing parameters imparts SFS with a versatility superior to most other silk spinning techniques.

This versatility, in turn, was exploited to guide the development of the technique by two basic principles: (i) Fibers had to be produced under environmentally friendly conditions, both in terms of the composition of the dope and focusing fluid and on the physicochemical parameters (i.e., $\mathrm{pH}$ or concentration of $\mathrm{Ca}^{2+}$ ions) required by the process; and (ii) it was necessary to find a set of processing conditions that led to the production of high-performance fibers. This review shows how both principles were fulfilled, so that high-performance silk fibers can be produced efficiently from silkworm silk fibroin solutions through SFS with the exclusive use of mild chemistries.

Although our previous studies have shown the possibilities of this technique, they have concentrated on a very limited range within the wide variety of possible conditions and opportunities. Thus, there are complete areas that remain unexplored, such as spinning from solutions of either natural spider silk spidroin or recombinant bioinspired silk proteins, just to mention a couple exciting possibilities. Consequently, a deeper exploration of SFS will probably have a significant influence in the future development of biomimetic production systems of high-performance and biocompatible fibers. These new materials, in turn, should have a significant impact on the production of new meta-materials, fabrics, scaffolds, and a large variety of products for numerous applications in the future.

\section{Patents}

Patent application of the SFS technology [57]. The SFS technology is licensed to Silk Biomed, S.L.

Funding: This research was funded by the Ministry of Economy and Competitiveness in Spain, grant numbers MAT2016-75544-C2-1-R, MAT2016-79832-R and CPI2016-78887-C3-1-R, and by Comunidad de Madrid, grant number NEUROCENTRO-B2017/BMD-3760.

Acknowledgments: Silkworm cocoons were kindly provided by José Luis Cenis (Instituto Murciano de Investigación y Desarrollo Agrario y Alimentario (IMIDA), Murcia, Spain).

Conflicts of Interest: The following authors appear as inventors of the patent (see Section 8): J.P.-R., R.M., A.M.G.-C., G.R.P., G.V.G. and M.E.

\section{References}

1. Heim, M.; Keerl, D.; Scheibel, T. Spider silk: From soluble protein to extraordinary fiber. Angew. Chem. Int. Ed. Engl. 2009, 48, 3584-3596. [CrossRef] [PubMed]

2. Selden, P.A.; Shear, W.A.; Sutton, M.D. Fossil evidence for the origin of spider spinnerets, and a proposed arachnid order. Proc. Natl. Acad. Sci. USA 2008, 105, 20781-20785. [CrossRef] [PubMed]

3. Craig, C.L.; Riekel, C. Comparative architecture of silks, fibrous proteins and their encoding genes in insects and spiders. Comp. Biochem. Physiol. B Biochem. Mol. Biol. 2002, 133, 493-507. [CrossRef]

4. Blackledge, T.A.; Pérez-Rigueiro, J.; Plaza, G.R.; Perea, B.; Navarro, A.; Guinea, G.V.; Elices, M. Sequential origin in the high performance properties of orb spider dragline silk. Sci. Rep. 2012, 2, 782. [CrossRef] [PubMed]

5. Kaplan, D.L.; Lombardi, S.; Muller, W.S.; Fossey, S.A. Biomaterials. Novel Materials from Biological Sources; Stockton Press: New York, NY, USA, 1991.

6. Xia, Q.Y.; Zhou, Z.Y.; Lu, C.; Cheng, D.J.; Dai, F.Y.; Li, B.; Zhao, P.; Zha, X.F.; Cheng, T.C.; Chai, C.L.; et al. A draft sequence for the genome of the domesticated silkworm (Bombyx mori). Science 2004, 306, 1937-1940. [CrossRef] [PubMed]

7. Gatesy, J.; Hayashi, C.; Motriuk, D.; Woods, J.; Lewis, R. Extreme diversity, conservation, and convergence of spider silk fibroin sequences. Science 2001, 291, 2603-2605. [CrossRef] [PubMed] 
8. Hagn, F.; Eisoldt, L.; Hardy, J.G.; Vendrely, C.; Coles, M.; Scheibel, T.; Kessler, H. A conserved spider silk domain acts as a molecular switch that controls fibre assembly. Nature 2010, 465, 239-242. [CrossRef] [PubMed]

9. Askarieh, G.; Hedhammar, M.; Nordling, K.; Saenz, A.; Casals, C.; Rising, A.; Johansson, J.; Knight, S.D. Self-assembly of spider silk proteins is controlled by a pH-sensitive relay. Nature 2010, 465, 236-239. [CrossRef] [PubMed]

10. Rising, A.; Johansson, J. Toward spinning artificial spider silk. Nat. Chem. Biol. 2015, 11, 309-315. [CrossRef] [PubMed]

11. Andersson, M.; Johansson, J.; Rising, A. Silk spinning in silkworms and spiders. Int. J. Mol. Sci. 2016, 17, 1290. [CrossRef] [PubMed]

12. Andersson, M.; Chen, G.; Otikovs, M.; Landreh, M.; Nordling, K.; Kronqvist, N.; Westermark, P.; Jornvall, H.; Knight, S.; Ridderstrale, Y.; et al. Carbonic anhydrase generates $\mathrm{CO}_{2}$ and $\mathrm{H}^{+}$that drive spider silk formation via opposite effects on the terminal domains. PLoS Biol. 2014, 12, e1001921. [CrossRef] [PubMed]

13. Terry, A.E.; Knight, D.P.; Porter, D.; Vollrath, F. pH induced changes in the rheology of silk fibroin solution from the middle division of Bombyx mori silkworm. Biomacromolecules 2004, 5, 768-772. [CrossRef] [PubMed]

14. Rammensee, S.; Slotta, U.; Scheibel, T.; Bausch, A.R. Assembly mechanism of recombinant spider silk proteins. Proc. Natl. Acad. Sci. USA 2008, 105, 6590-6595. [CrossRef] [PubMed]

15. Hardy, J.G.; Romer, L.M.; Scheibel, T.R. Polymeric materials based on silk proteins. Polymer 2008, 49, 4309-4327. [CrossRef]

16. Holland, C.; Terry, A.E.; Porter, D.; Vollrath, F. Comparing the rheology of native spider and silkworm spinning dope. Nat. Mater. 2006, 5, 870-874. [CrossRef] [PubMed]

17. Mo, C.L.; Holland, C.; Porter, D.; Shao, Z.Z.; Vollrath, F. Concentration state dependence of the rheological and structural properties of reconstituted silk. Biomacromolecules 2009, 10, 2724-2728. [CrossRef] [PubMed]

18. Vollrath, F.; Knight, D.P. Liquid crystalline spinning of spider silk. Nature 2001, 410, 541-548. [CrossRef] [PubMed]

19. Jin, H.J.; Kaplan, D.L. Mechanism of silk processing in insects and spiders. Nature 2003, 424, $1057-1061$. [CrossRef] [PubMed]

20. Iizuka, E. Silk thread-Mechanism of spinning and its mechanical-properties. J. Appl. Polym. Sci. Appl. Polym. Symp. 1985, 41, 173-185.

21. Ortlepp, C.; Gosline, J. Consequences of forced silking. Biomacromolecules 2004, 5, 727-731. [CrossRef] [PubMed]

22. Marsh, R.E.; Corey, R.B.; Pauling, L. An investigation of the structure of silk fibroin. Biochim. Biophys. Acta 1955, 16, 1-34. [CrossRef]

23. Takahashi, Y.; Gehoh, M.; Yuzuriha, K. Structure refinement and diffuse streak scattering of silk (Bombyx mori). Int. J. Biol. Macromol. 1999, 24, 127-138. [CrossRef]

24. Madurga, R.; Blackledge, T.A.; Perea, B.; Plaza, G.R.; Riekel, C.; Burghammer, M.; Elices, M.; Guinea, G.; Perez-Rigueiro, J. Persistence and variation in microstructural design during the evolution of spider silk. Sci. Rep. 2015, 5, 14820. [CrossRef] [PubMed]

25. Cenis, J.L.; Madurga, R.; Aznar-Cervantes, S.D.; Lozano-Perez, A.A.; Mari-Buye, N.; Meseguer-Olmo, L.; Plaza, G.R.; Guinea, G.V.; Elices, M.; del Pozo, F.; et al. Mechanical behaviour and formation process of silkworm silk gut. Soft Matter 2015, 11, 8981-8991. [CrossRef] [PubMed]

26. Hoffmann, B.; Gruat-Henry, C.; Mulinti, P.; Jiang, L.; Brooks, B.D.; Brooks, A.E. Using hydrodynamic focusing to predictably alter the diameter of synthetic silk fibers. PLOS ONE 2018, 13, e0195522. [CrossRef] [PubMed]

27. Yazawa, S. Spinning of concentrated aqueous silk fibroin solution. J. Chem. Soc. Jpn. 1960, 63, 1428-1430.

28. Ishizaka, H.; Watanabe, Y.; Ishida, K.; Fukumoto, O. Regenerated silk prepared from ortho phosphoric acid solution of fibroin. J. Ser. Sci. Jpn. 1989, 58, 87-95.

29. Yao, J.M.; Masuda, H.; Zhao, C.H.; Asakura, T. Artificial spinning and characterization of silk fiber from Bombyx mori silk fibroin in hexafluoroacetone hydrate. Macromolecules 2002, 35, 6-9. [CrossRef]

30. Um, I.C.; Kweon, H.Y.; Lee, K.G.; Ihm, D.W.; Lee, J.H.; Park, Y.H. Wet spinning of silk polymer-I. Effect of coagulation conditions on the morphological feature of filament. Int. J. Biol. Macromol. 2004, 34, 89-105. [CrossRef] [PubMed] 
31. Um, I.C.; Ki, C.S.; Kweon, H.Y.; Lee, K.G.; Ihm, D.W.; Park, Y.H. Wet spinning of silk polymer-II. Effect of drawing on the structural characteristics and properties of filament. Int. J. Biol. Macromol. 2004, 34, 107-119. [CrossRef] [PubMed]

32. Zhang, F.; Lu, Q.; Yue, X.; Zuo, B.; Qin, M.; Li, F.; Kaplan, D.L.; Zhang, X. Regeneration of high-quality silk fibroin fiber by wet spinning from $\mathrm{CaCl}_{2}$-formic acid solvent. Acta Biomater. 2015, 12, 139-145. [CrossRef] [PubMed]

33. Jin, Y.; Zhang, Y.; Hang, Y.; Shao, H.; Hu, X. A simple process for dry spinning of regenerated silk fibroin aqueous solution. J. Mater. Res. 2013, 28, 2897-2902. [CrossRef]

34. Yue, X.; Zhang, F.; Wu, H.; Ming, J.; Fan, Z.; Zuo, B. A novel route to prepare dry-spun silk fibers from $\mathrm{CaCl}_{2}$-formic acid solution. Mater Lett. 2014, 128, 175-178. [CrossRef]

35. Plaza, G.R.; Corsini, P.; Marsano, E.; Perez-Rigueiro, J.; Biancotto, L.; Elices, M.; Riekel, C.; Agullo-Rueda, F.; Gallardo, E.; Calleja, J.M.; et al. Old silks endowed with new properties. Macromolecules 2009, 42, 8977-8982. [CrossRef]

36. Jin, H.J.; Fridrikh, S.; Rutledge, G.C.; Kaplan, D. Electrospinning Bombyx mori silk with poly(ethylene oxide). Abstr. Pap. Am. Chem. Soc. 2002, 224, U431.

37. Kim, S.H.; Nam, Y.S.; Lee, T.S.; Park, W.H. Silk fibroin nanofiber. Electrospinning, properties, and structure. Polym. J. 2003, 35, 185-190. [CrossRef]

38. Zhu, J.; Zhang, Y.; Shao, H.; Hu, X. Electrospinning and rheology of regenerated Bombyx mori silk fibroin aqueous solutions: The effects of $\mathrm{pH}$ and concentration. Polymer 2008, 49, 2880-2885. [CrossRef]

39. Solanas, C.; Herrero, S.; Dasari, A.; Plaza, G.R.; Llorca, J.; Perez-Rigueiro, J.; Elices, M.; Guinea, G.V. Insights into the production and characterization of electrospun fibers from regenerated silk fibroin. Eur. Polym. J. 2014, 60, 123-134. [CrossRef]

40. Luo, J.; Zhang, L.; Peng, Q.; Sun, M.; Zhang, Y.; Shao, H.; Hu, X. Tough silk fibers prepared in air using a biomimetic microfluidic chip. Int. J. Biol. Macromol. 2014, 66, 319-324. [CrossRef] [PubMed]

41. Tokareva, O.; Jacobsen, M.; Buehler, M.; Wong, J.; Kaplan, D.L. Structure-function-property-design interplay in biopolymers: Spider silk. Acta Biomater. 2014, 10, 1612-1626. [CrossRef] [PubMed]

42. Heidebrecht, A.; Eisoldt, L.; Diehl, J.; Schmidt, A.; Geffers, M.; Lang, G.; Scheibel, T. Biomimetic fibers made of recombinant spidroins with the same toughness as natural spider silk. Adv. Mater. 2015, 27, 2189-2194. [CrossRef] [PubMed]

43. Anton, A.M.; Heidebrecht, A.; Mahmood, N.; Beiner, M.; Scheibel, T.; Kremer, F. Foundation of the outstanding toughness in biomimetic and natural spider silk. Biomacromolecules 2017, 18, 3954-3962. [CrossRef] [PubMed]

44. Andersson, M.; Jia, Q.; Abella, A.; Lee, X.; Landreh, M.; Purhonen, P.; Hebert, H.; Tenje, M.; Robinson, C.V.; Meng, Q.; et al. Biomimetic spinning of artificial spider silk from a chimeric minispidroin. Nat. Chem. Biol. 2017, 13, 262-264. [CrossRef] [PubMed]

45. Madurga, R.; Ganan-Calvo, A.M.; Plaza, G.R.; Guinea, G.V.; Elices, M.; Perez-Rigueiro, J. Production of high performance bioinspired silk fibers by straining flow spinning. Biomacromolecules 2017, 18, 1127-1133. [CrossRef] [PubMed]

46. Madurga, R.; Ganan-Calvo, A.M.; Plaza, G.R.; Guinea, G.V.; Elices, M.; Perez-Rigueiro, J. Straining flow spinning: Production of regenerated silk fibers under a wide range of mild coagulating chemistries. Green Chem. 2017, 19, 3380-3389. [CrossRef]

47. Madurga, R.; Guinea, G.V.; Elices, M.; Perez-Rigueiro, J.; Ganan-Calvo, A.M. Straining flow spinning: Simplified model of a bioinspired process to mass produce regenerated silk fibers controllably. Eur. Polym. J. 2017, 97, 26-39. [CrossRef]

48. Madurga, R.; Gañán-Calvo, A.M.; Plaza, G.R.; Atienza, J.M.; Guinea, G.V.; Elices, M.; López, P.A.; Daza, R.; González-Nieto, D.; Pérez-Rigueiro, J. Comparison of the effects of post-spinning drawing and wet stretching on regenerated silk fibers produced through straining flow spinning. Polymer 2018, 150, 311-317. [CrossRef]

49. Madurga, R.; Gañán-Calvo, A.; Mariscal, T.; Plaza, G.R.; Guinea, G.V.; Elices, M.; Perez-Rigueiro, J. Production of regenerated silkworm silk fibers from aqueous dopes through straining flow spinning. Text. Res. J. 2018. submitted for publication.

50. Ganan-Calvo, A.M. Generation of steady liquid microthreads and micron-sized monodisperse sprays in gas streams. Phys. Rev. Lett. 1998, 80, 285-288. [CrossRef] 
51. Ganan-Calvo, A.M.; Montanero, J.M. Revision of capillary cone-jet physics: Electrospray and flow focusing. Phys. Rev. E 2009, 79, 069905. [CrossRef]

52. Perez-Rigueiro, J.; Viney, C.; Llorca, J.; Elices, M. Silkworm silk as an engineering material. J. Appl. Polym. Sci. 1998, 70, 2439-2447. [CrossRef]

53. Guinea, G.V.; Elices, M.; Perez-Rigueiro, J.; Plaza, G.R. Stretching of supercontracted fibers: A link between spinning and the variability of spider silk. J. Exp. Biol. 2005, 208, 25-30. [CrossRef] [PubMed]

54. Marsano, E.; Corsini, P.; Arosio, C.; Boschi, A.; Mormino, M.; Freddi, G. Wet spinning of Bombyx mori silk fibroin dissolved in $\mathrm{N}$-methyl morpholine $\mathrm{N}$-oxide and properties of regenerated fibres. Int. J. Biol. Macromol. 2005, 37, 179-188. [CrossRef] [PubMed]

55. Corsini, P.; Perez-Rigueiro, J.; Guinea, G.V.; Plaza, G.R.; Elices, M.; Marsano, E.; Carnasciali, M.M.; Freddi, G. Influence of the draw ratio on the tensile and fracture behavior of NMMO regenerated silk fibers. J. Polym. Sci. Part B Polym. Phys. 2007, 45, 2568-2579. [CrossRef]

56. Corsini, P. New Fibres Based on Natural Polymers: Silk and Cellulose. Ph.D. Thesis, Universita degli Studi di Genova, Genova, Italy, 2008.

57. Pérez-Rigueiro, J.; Guinea Tortuero, G.V.; Elices Calafat, M.; Plaza Baonza, G.R.; Madurga Lacalle, R.; Gañán Calvo, A.M. Method for Producing Elongated Structures such as Fibers from Polymer Solutions by Straining Flow Spinning. European Patent No. EP15382646, 18 December 2015.

(C) 2018 by the authors. Licensee MDPI, Basel, Switzerland. This article is an open access article distributed under the terms and conditions of the Creative Commons Attribution (CC BY) license (http://creativecommons.org/licenses/by/4.0/). 